\title{
Docusate Calcium
}

National Cancer Institute

\section{Source}

National Cancer Institute. Docusate Calcium. NCI Thesaurus. Code C28999.

The calcium salt of docusate, a dioctyl salt and an emollient laxative with stool-softening activity. Docusate decreases surface tension and emulsification of fecal matter and allows water to penetrate and mix with stool. As a result, it softens the stool. 